\title{
DIREITO HUMANO À ALIMENTAÇÃO ADEQUADA: PERCEPÇÕES E PRÁTICAS DE NUTRICIONISTAS A PARTIR DO AMBIENTE ESCOLAR
}

\author{
HUMAN RIGHT TO ADEQUATE FOOD: PERCEPTIONS AND PRACTICES OF NUTRITIONISTS IN A \\ SCHOOL ENVIRONMENT
}

\section{DERECHO HUMANO A LA ALIMENTACIÓN ADECUADA: PERCEPCIONES Y PRÁCTICAS DE NUTRICIONISTAS EN AMBIENTE ESCOLAR}

\author{
Carla Rosane Paz Arruda Teo ${ }^{1}$ \\ Luciara Souza Gallina ${ }^{2}$ \\ Maria Assunta Busato ${ }^{3}$
}

Resumo A incorporação da perspectiva dos direitos e da cidadania às políticas públicas de alimentação e nutrição passa pela prática social dos atores envolvidos com a concretização dessas políticas. O objetivo do estudo foi compreender percepções e práticas de nutricionistas sobre o direito humano à alimentação adequada no âmbito de sua atuação profissional no Programa Nacional de Alimentação Escolar. O estudo, desenvolvido em 2014, foi qualitativo, e a coleta de dados, realizada por grupo focal. Participaram 11 nutricionistas de municípios da Mesorregião Oeste Catarinense. As falas foram gravadas, transcritas e analisadas segundo a técnica de análise de conteúdo temática. Os resultados indicaram que as participantes tinham percepção abrangente sobre o direito humano à alimentação adequada, em diferentes dimensões e relações com os aspectos inerentes a ela. As nutricionistas destacaram a importância e o desafio da atuação intersetorial, articulada à comunidade. Contudo, pareceu haver limitação ao trabalho em equipe e à interlocução com as famílias, possivelmente por fragilidade de suporte teórico-metodológico e político para intervenção nesse campo. As percepções abrangentes das nutricionistas, mas pouco fundamentadas teórica e politicamente sobre o direito humano à alimentação adequada, evidenciaram o desafio a se enfrentar na formação profissional, tanto na graduação como na educação permanente.

Palavras-chave alimentação escolar; ação intersetorial; direitos humanos; educação superior; políticas públicas.

\author{
Taíne Paula Cibulski ${ }^{4}$ \\ Tamara Becker ${ }^{5}$
}

\begin{abstract}
Incorporating the perspective of rights and citizenship to public policies on food and nutrition goes through the social practice of the players involved in the implementation of these policies. The aim of the study was to understand the nutritionists' perceptions and practices on the human right to adequate food in the context of their professional activities in the National Program for School Feeding. The study was qualitative, developed in 2014, and data were collected by means of a focus group. Eleven nutritionists from municipalities located in the West Santa Catarina Mesoregion (Brazil) participated. The statements were recorded, transcribed, and analyzed according to the thematic content analysis technique. The results showed that the participants had a comprehensive perception of the human right to adequate food, in different dimensions and relations with the aspects related to it. The nutritionists emphasized the importance and the challenge of intersectoral action linked to the community. However, there appeared to be a limitation in teamwork and in dialog with the families, possibly due to fragile theoretical-methodological and political support for intervention in this field. The nutritionists' comprehensive perceptions on the human right to adequate food, although poorly substantiated from the theoretical and political viewpoint, showed the challenge to be faced in vocational training, both in undergraduate and in permanent education.
\end{abstract}

Keywords school feeding; intersectoral action; human rights; college education; public policy. 


\title{
Introdução
}

\author{
A alimentação humana é um complexo processo \\ de transformação de natureza em gente, \\ em seres humanos, ou seja, em humanidade.
}

(Valente, 2002, p. 105).

O direito à alimentação adequada é um direito humano básico, sem o qual não podem ser discutidos ou concretizados outros direitos, uma vez que sua realização é imprescindível para o direito à vida (Valente, 2001).

$\mathrm{O}$ direito humano à alimentação adequada (DHAA) vem se construindo $\mathrm{e}$ consolidando ao longo do tempo, tendo origem na Declaração Universal dos Direitos Humanos, documento em que ficou estabelecido que "Toda pessoa tem direito a um padrão de vida capaz de assegurar a si e a sua família saúde e bem-estar, inclusive alimentação, vestuário, habitação" (Organização das Nações Unidas, 1948, artigo 25, § $1^{\circ}$ ).

Posteriormente, o Pacto Internacional dos Direitos Econômicos, Sociais e Culturais (Pidesc), adotado pela Organização das Nações Unidas (ONU) em 1966, em vigência internacional desde 1976 e ratificado pelo Brasil em 1992 (Brasil, 1992), reafirmou esse conceito e acrescentou que todas as pessoas têm o direito "a uma melhoria contínua de suas condições de existência" (Organização das Nações Unidas, 1966, artigo 11, § $1^{\circ}$ ).

Em 1999, conforme consta no Comentário geral n. 12, o Comitê de Direitos Econômicos, Sociais e Culturais do Alto Comissariado de Direitos Humanos da ONU definiu que o DHAA é realizado quando "cada homem, mulher e criança, sozinho ou em companhia de outros, tem acesso físico e econômico, ininterruptamente, à alimentação adequada ou aos meios para sua obtenção" (Organização das Nações Unidas, 1999, § 6º).

Esses tratados internacionais respaldam a ideia, corroborada no Marco estratégico global para a segurança alimentar e nutricional: consenso global, de que os estados signatários assumem obrigações no sentido de "respeitar, proteger e cumprir o direito humano à alimentação adequada mediante políticas globais, regionais e nacionais" (FAO, 2014, p. 6).

Reforça-se, assim, a ideia de que o direito de se alimentar regular e adequadamente não deve ser produto de benemerência, mas prioritariamente de uma obrigação que é exercida pelo Estado - representação da sociedade (Belik, 2003). Nessa perspectiva, o direito à alimentação adequada deve ser assegurado por meio de políticas públicas de segurança alimentar e nutricional (SAN) de responsabilidade do Estado e da sociedade (Maluf, 2011), de maneira que a SAN seja conquistada na medida em que o DHAA seja progressivamente realizado. 
No Brasil, há várias décadas vêm sendo construídas políticas públicas voltadas para a melhoria da SAN da população (Kepple e Segall-Corrêa, 2011), cabendo, neste ponto, a menção a dois momentos emblemáticos desse percurso: o da aprovação da lei n. 11.346/2006 (Brasil, 2006), conhecida como Lei Orgânica de Segurança Alimentar e Nutricional (Losan), e o da inserção da alimentação entre os direitos sociais positivados na Constituição Federal, por meio da emenda n. 64/2010 (Brasil, 2010a).

Atualmente, são muitas as políticas públicas voltadas para a garantia do DHAA e da SAN em execução no país. A implementação dessas políticas tem colocado em relevo a importância da atuação do nutricionista (Vieira, Utikava e Cervato-Mancuso, 2013). Destaca-se o Programa Nacional de Alimentação Escolar (PNAE), que é o mais antigo programa social do governo federal brasileiro na área de alimentação e nutrição e com objetivos voltados para a SAN, sendo considerado um eixo das políticas desse campo (Brasil, 2010b).

O programa, que tem origem na década de 1940 e marco legal instituído em 1955 (Chaves et al., 2007), é reconhecido como um dos maiores do mundo na área da alimentação escolar, atendendo de forma universal aproximadamente 43 milhões de estudantes da educação básica em todo o país, com orçamento de cerca de 3,3 bilhões de reais (FNDE, 2013). Esses números indicam a relevância e o potencial do programa para a realização do DHAA e da SAN no país, o que é reforçado pelo reconhecimento da alimentação escolar como direito social na Constituição Federal (Brasil, 1988).

Recentemente, a legislação que rege o PNAE foi reformulada, a partir da lei n. 11.947/2009, na qual a alimentação escolar é ratificada como direito dos estudantes da educação básica pública e dever do Estado, visando garantir a SAN. Esse marco legal atribui a responsabilidade técnica pelo programa ao profissional nutricionista, no âmbito de suas atribuições específicas (Brasil, 2009).

Nesse cenário, diante da relevância do PNAE em termos de sua longevidade, abrangência e pelo fato de ser desenvolvido em um espaço legitimamente reconhecido como privilegiado para os processos de aprendizagem - a escola -, importa considerar se, para além do atendimento de seus objetivos operacionais, o programa efetivamente tem incorporada em sua execução cotidiana a perspectiva do DHAA, delimitação na qual ainda são escassos os estudos (Siqueira et al., 2014).

Cabe mencionar que a incorporação da perspectiva do DHAA às políticas públicas passa, entre outros aspectos, pelo desenvolvimento e apropriação de uma 'cultura dos direitos' pelos diversos atores sociais envolvidos, como gestores, servidores públicos e população (Valente e Beghin, 2006).

Ao se considerar, nesse contexto, a centralidade do DHAA para a conquista de níveis superiores de SAN, é importante compreender como os 
profissionais da nutrição percebem e incorporam, na sua prática, tais questões. Argumenta-se que compreender as percepções que orientam as práticas de nutricionistas a respeito desses temas pode contribuir para que sejam repensados e qualificados os processos de formação e de atuação profissional.

Diante desse panorama, o estudo apresentado neste artigo teve como objetivo compreender as percepções e as práticas de nutricionistas sobre o DHAA no âmbito de sua atuação profissional no PNAE.

\section{O percurso metodológico: acessando as percepções e as práticas}

O estudo, desenvolvido em 2014, teve abordagem qualitativa com coleta de dados realizada pela técnica de grupo focal, que consiste na reunião de um grupo de pessoas para avaliar conceitos, aprofundar conhecimentos ou identificar problemas sobre uma temática. Essa técnica permite identificar representações, percepções, atitudes e sentimentos dos participantes a respeito de determinado assunto, a partir de um processo de discussão focada em um ou alguns poucos tópicos específicos. Para tanto, é importante que os participantes partilhem algum traço ou característica relevante para o estudo pretendido, o que permite compreender os processos de construção da realidade e as práticas cotidianas no âmbito desse grupo (Gatti, 2012).

Nesta pesquisa, o critério adotado foi a condição de o nutricionista atuar como responsável técnico (RT) pelo PNAE em municípios da Mesorregião Oeste Catarinense, espaço de inserção da universidade que desenvolveu este estudo, sendo esta uma característica em comum importante para a composição do grupo focal.

Foram convidados a participar do estudo os nutricionistas RTs do PNAE atuantes em vinte municípios dessa mesorregião, tendo sido amplamente esclarecidos sobre os objetivos e procedimentos de pesquisa. Aqueles que aceitaram assinaram os termos de consentimento livre e esclarecido e de consentimento de uso de voz. Em seguida, em atendimento às recomendações de Minayo (2010), o grupo foi constituído por 11 nutricionistas que atuavam em diferentes municípios da região delimitada, os quais foram reunidos em local de sua escolha, em sessão com duração aproximada de duas horas.

Nessa ocasião, coletaram-se inicialmente dados individuais de identificação de cada participante. Em seguida, para conduzir as atividades de coleta de dados no grupo, foram utilizadas as seguintes perguntas norteadoras: 'para vocês, o que é o direito humano à alimentação adequada?'; 'como, ou em que situações, vocês percebem que este direito é violado?'; 'vocês percebem este direito presente no dia a dia do trabalho no PNAE?'; e 'que fatores dificultam a realização deste direito a partir do PNAE?'. 
As falas das participantes foram gravadas, transcritas e analisadas segundo técnica de análise de conteúdo temática, em três etapas: pré-análise; exploração do material; tratamento dos resultados obtidos e interpretação (Minayo, 2010). A análise foi pautada pelas categorias analíticas definidas a priori, de acordo com o objetivo da pesquisa: 'as percepções que orientam as práticas'; e 'das percepções às práticas, os desafios'.

Para cada categoria analítica prévia, buscou-se reconhecer as convergências e divergências de significados presentes nos depoimentos das participantes, e trechos de suas falas, identificadas por nomes de flores, foram apresentados ao longo do texto para ilustrar os achados principais das análises e sua teorização.

O projeto que deu origem a este estudo foi aprovado pelo Comitê de Ética em Pesquisa da Universidade Comunitária da Região de Chapecó (Unochapecó) (parecer n. 080/10), tendo sido rigorosamente respeitadas todas as diretrizes e normas regulamentadoras de pesquisas envolvendo seres humanos (Brasil, 2012).

\section{Reconhecendo os sujeitos e o contexto}

Participaram do estudo 11 nutricionistas, mulheres, entre 25 e 34 anos, atuando como responsáveis técnicos pelo PNAE em municípios de pequeno porte da Mesorregião Oeste Catarinense, com populações estimadas variando entre 2.046 e 10.236 habitantes (Instituto Brasileiro de Geografia e Estatística, 2014) e com índices de desenvolvimento humano municipal (IDHM) entre 0,691 e 0,773 (Programa das Nações Unidas para o Desenvolvimento, 2013). As informações sobre local e tempo de formação inicial (graduação) e sobre tempo de atuação na ocupação atual estão apresentadas na Tabela 1.

Tabela 1

\begin{tabular}{ll}
$\begin{array}{l}\text { Perfil de formação e atuação profissional das nutricionistas participantes do estudo. } \\
\text { Oeste de Santa Catarina, } 2014\end{array}$ & $\mathbf{n}$ \\
\hline \multicolumn{1}{c}{ Variável } & \\
\hline Tempo de formação inicial & 02 \\
Até 2 anos & 05 \\
De 3 a 4 anos & 04 \\
De 5 a 6 anos & \\
Local de formação inicial & 02 \\
Rio Grande do Sul & 06 \\
Santa Catarina & 03 \\
Paraná & \\
Tempo de atuação na ocupação atual & 07 \\
Até 2 anos & 03 \\
De 3 a 4 anos & 01 \\
De 5 a 6 anos &
\end{tabular}

Fonte: As autoras. 
A análise dos depoimentos das participantes foi feita com base nas categorias analíticas definidas a priori e, dentro de cada uma delas, as percepções dos sujeitos produziram sentidos que foram explorados no processo de compreensão e interpretação apresentado a seguir.

\section{As percepções que orientam as práticas}

Os diversos tratados internacionais no campo dos direitos humanos reconhecem a existência de duas dimensões, indivisíveis, implicadas no DHAA: a do direito de estar protegido da fome e a do direito de ter acesso a uma alimentação adequada (Organização das Nações Unidas, 1966, 1999; Brasil, 1992; FAO, 2014). Assim, evidencia-se que a realização do DHAA pressupõe o acesso alimentar de forma regular e permanente - protegendo contra a fome - e também que a alimentação acessada seja adequada (Brasil, 2009). Já uma alimentação adequada implica adequação nutricional, diversidade, inocuidade, adequação cultural, acesso à informação e aos recursos (financeiros e naturais) para sua obtenção sem comprometimento da realização de outros direitos (Organização das Nações Unidas, 1999; Leão e Recine, 2011).

Neste estudo, ao serem provocadas a debater os significados do DHAA e as situações que representam violações desse direito, as nutricionistas evidenciaram percebê-lo em sua amplitude, apontando suas dimensões e vários aspectos implicados com a adequação da alimentação, conforme ilustraram as falas apresentadas a seguir:

Não é só o acesso à alimentação, como o acesso a saneamento básico, moradia adequada, condições de higiene, além da alimentação. As pessoas têm o acesso aos alimentos em quantidade suficiente, mas não têm qualidade. Desde a qualidade e a inspeção da carne, por exemplo, tudo isso envolve o DHAA. Tem que ter quantidade suficiente e, principalmente, qualidade. Acho que tudo isso envolve o DHAA, não só a questão do acesso (Dália).

Talvez as pessoas não consigam ter tanta diversidade de alimentos, atingir todos os grupos alimentares como a gente oferece nas escolas... (Tulipa).

Você mexe com algo cultural, então é algo bem mais complexo! Eu coloco salame na alimentação escolar: se eu não colocar, eles me cobram, né? É hábito da nossa população comer... (Girassol).

São outras coisas básicas que as pessoas não têm. A gente pensa na alimentação, mas tem tantas outras coisas, desde vestuário, tudo... (Cravo). 
As falas indicaram uma percepção abrangente do DHAA, evidenciando que as participantes compreenderam o direito para além do acesso aos alimentos, incluindo sua adequação nutricional e cultural, diversidade e inocuidade, assim como a realização concomitante de outros direitos, que não deveriam estar comprometidos e de cuja plena efetivação depende o direito humano à alimentação adequada. Na mesma direção, surgiram na discussão do grupo as questões do acesso à informação e aos meios para obtenção de uma alimentação adequada:

O que tem é falta de conhecimento dos pais de usarem os alimentos adequados. Tem bastante mãe que, ao invés de comprar os ingredientes pra fazer a comida pros seus filhos, compram macarrão instantâneo, achando que estão fazendo uma grande coisa! Porque elas não têm conhecimento, né? (Cravo).

[Conhecimento] Pra usar o dinheiro de forma adequada... (Begônia).

É, mas na minha realidade, que é um município que tem uma área rural muito grande, as pessoas não plantam! A horta deles se resume a um pé de alface, cenoura e ponto final, tendo espaço pra um bom cultivo. Então, parece que o pessoal fica acomodado: 'Ah, eu vou no mercado e compro o que dá, mas não é sempre que eu consigo comprar fruta.' Mas não mora no interior? Não tem uma área de terra? Não consegue plantar? (Bromélia).

Destaca-se esta observação como um aspecto positivo deste estudo, que demonstrou que as profissionais percebiam o DHAA inserido em uma conjuntura mais alargada do que apenas a das questões técnicas específicas da área da alimentação e nutrição. Diferentemente, Ramos e Cuervo (2012) constataram desconhecimento ou conhecimento incipiente sobre o DHAA em profissionais de unidades básicas de saúde em Porto Alegre (RS), incluindo nutricionistas, chegando à conclusão de que os profissionais da área da saúde têm pouca aproximação com a problemática dos direitos humanos, tanto no âmbito teórico quanto no prático.

Outros elementos, apresentados no debate do grupo, corroboraram uma percepção abrangente do DHAA neste estudo, como o reconhecimento de diferentes expressões de sua violação, as quais se manifestam também pelo consumo excessivo de alimentos ou de alimentos não saudáveis (Siqueira et al., 2014).

Vem o contraste, porque a gente vem discutindo o que fazer pra diminuir o índice de obesidade, sobrepeso, pra fazer promoção da alimentação saudável... Discutindo sobre como enfrentar a obesidade com essas crianças que têm o acesso à alimentação assegurado (Dália). 
Depreende-se da fala, portanto, que a observação de um número crescente de casos de sobrepeso e obesidade entre os escolares seria - para esse grupo - um indicativo de que o público assistido teria garantido seu acesso à alimentação. Contudo, cabe destacar que as participantes perceberam essa condição como uma violação do DHAA, pautando suas reflexões pela ideia de que viver em insegurança alimentar também passa pelo sobrepeso (Poblacion et al., 2014), como indicaram nos seguintes trechos:

Se for ver, tem muita criança em risco de má alimentação, tanto no sentido da falta, mesmo, como no sentido do excesso (Cravo).

Em muitas situações você faz a avaliação e classifica a criança como eutrófica, mas ela chegou a essa condição a partir de que tipo de alimentação? Uma alimentação variada, fonte de diversos nutrientes, ou uma alimentação inadequada? (Girassol).

Tem a questão de não atingir os nutrientes adequados (Tulipa).

Provavelmente, essa constatação se deveu às características dos municípios nos quais as nutricionistas atuavam, todos de pequeno porte, com fortes características de ruralidade e com IDHM entre médio e alto. Entretanto, pontua-se que tem sido recorrentemente relatada na literatura a prevalência das condições de sobrepeso e obesidade de forma generalizada no Brasil, tanto entre escolares quanto na população em geral (Instituto Brasileiro de Geografia e Estatística, 2010; Brasil, 2014), o que indica que essa problemática não representa uma demanda local ou uma especificidade regional.

No curso da discussão sobre essa questão, as nutricionistas relataram índices de sobrepeso e obesidade somados variando de $18 \%$ a $35 \%$ entre os escolares do ensino fundamental dos municípios em que atuavam. Portanto, assumindo-se que o excesso de peso - decorrente do consumo alimentar inadequado - é uma dentre as expressões de violação do DHAA, pode-se estimar que sua ocorrência seja ainda mais acentuada se for considerado o progressivo número de casos de doenças crônicas não transmissíveis associadas à má alimentação (Siqueira et al., 2014).

Prosseguindo a discussão, as participantes foram motivadas a explorar outras possíveis situações de violação do DHAA como um recurso para, no contraditório, acessar suas percepções sobre os sentidos desse direito. Nesse ponto, o grupo manifestou que, nos seus espaços de atuação profissional, no que tangia à dimensão de estar livre da fome, o DHAA vinha sendo mais significativamente realizado, apontando outras formas de violação: 
Na minha realidade, não acredito que tenha alguma família que passe fome... O trabalho social é muito grande nesse sentido, principalmente em alimentos. O que tem é falta de conhecimento dos pais de usarem os alimentos adequados (Cravo).

Tem muita gente que tem conhecimento, mas tem uma série de fatores aí... (Margarida).

Tem o preço... (Rosa).

Mas é muito mais fácil dar um salgadinho, uma bolachinha, a criança passa a tarde inteira assistindo televisão enquanto a mãe limpa a casa. Então, as pessoas podem ter acesso ao alimento e à informação, porém não usam isso a seu favor (Bromélia).

Contudo, as participantes reconheceram que existiam famílias em condições de elevada vulnerabilidade no território de estudo, no tocante à realização do DHAA em suas duas dimensões:

Eu acho que tem, sim, dificuldades de acesso além dos problemas de qualidade. Tem famílias carentes. Tem alunos na creche que os pais vêm do interior, acordam às cinco da manhã. Trabalham na fábrica na cidade. Então, as crianças ficam em tempo integral na creche. Chegam em casa por volta das sete horas da noite. Essa mãe não tem como ter uma horta, por exemplo. Não tem tempo para se dedicar a isso, e a renda deles é muito baixa, um salário mínimo e é esse o salário, então dificulta o acesso e a qualidade (Gerânio).

Note-se que essa fala relativizou a suposta falta de conhecimento e informação dos pais - como apontado anteriormente - e inseriu outros elementos no debate, os quais são respaldados pelo Comentário geral $n .12$ da ONU, que salienta o DHAA como uma questão de responsabilidade compartilhada. O documento ressalta que os estados são signatários do Pidesc, responsáveis primeiros pelo cumprimento de seus termos, motivo pelo qual devem aportar as condições necessárias para que os demais atores envolvidos - indivíduos, famílias, comunidades locais, organizações não governamentais, organizações da sociedade civil e do setor empresarial - assumam suas responsabilidades com relação à realização do DHAA (Organização das Nações Unidas, 1999).

De todo modo, ao apontar que as escolhas alimentares são também mediadas por outros determinantes de natureza estruturante, como a renda, a fala aqui citada atenuou uma possível culpabilização das famílias, evidenciando uma capacidade de leitura da realidade que reconhece sua 
vulnerabilidade social e, certamente, propicia e qualifica a intervenção profissional nesse contexto.

Entretanto, apesar de perceberem o DHAA em suas dimensões fundamentais, demonstrando uma visão que abrange os mais diversos fatores implicados na adequação da alimentação, constatou-se pouca capacidade de aprofundamento dos elementos trazidos para o debate. Esta observação condiz com estudo de Vieira, Utikava e Cervato-Mancuso (2013), no qual as autoras relataram uma visão relativamente superficial do nutricionista sobre a atuação no campo da SAN, creditando-a a fragilidades nos processos de formação.

Cabe considerar ainda que, a despeito da abrangência mencionada, predominou no grupo a abordagem do direito a partir do aspecto de proteção contra a fome, assegurada pelo acesso regular e permanente a alimentos. De maneira similar, Machado (2009) refere que a ideia de direito à saúde, no Brasil, tem estado resumida à perspectiva do acesso, nesse caso a bens e serviços de saúde. O autor alerta que essa concepção reduzida contrapõe a trajetória histórica empreendida por diversos atores sociais em prol da construção do direito à saúde como direito de cidadania.

Argumenta-se, neste estudo, que a mesma lógica pode ser proposta com relação ao DHAA, sendo fundamental sua superação para a promoção de avanços na realização desse direito. Assim, a ausência - nas discussões do grupo - de aspectos relativos à dignidade humana merece registro. Ressalta-se que a proteção contra a fome (decorrente do acesso aos alimentos) "é o patamar mínimo da dignidade humana, mas não pode ser dissociado do direito a uma alimentação de qualidade, do direito de obter este alimento com dignidade, através do seu próprio esforço" (Valente, 2001, p. 2). O fato de que as participantes tenham creditado a garantia do acesso aos alimentos, pelo menos em parte, à existência de diversos programas sociais, sem que tivesse sido problematizada a questão da construção, pelas famílias, da capacidade de obtenção de uma alimentação adequada e a sua relação com a dignidade - inerente ao DHAA -, permanece como um não dito importante.

Uma segunda ausência relevante observada neste estudo precisa ser apontada: a questão da sustentabilidade. Essa categoria está intrinsecamente ligada à noção de alimentação adequada, referindo-se, no âmbito do DHAA, a aplicar uma perspectiva intergeracional à disponibilidade alimentar, considerando a condição de o alimento estar disponível na atualidade e também para as futuras gerações (Organização das Nações Unidas, 1999).

Sublinha-se a relevância desse não dito, uma vez que os princípios teóricos, legais e políticos do DHAA o vinculam explicitamente à saúde, ao ambiente e aos modelos de desenvolvimento, os quais estão imbricados na causalidade de desafios como a fome, o aumento da obesidade, a crise energética e as ameaças à biodiversidade, cujos efeitos transcendem grupos ou fronteiras regionais (Magalhães, 2014). 
Entre os não ditos, cabe, finalmente, registrar o fato de não ter sido mencionada, no debate do grupo, a disponibilidade de alimentos, característica fundamental do ambiente alimentar. Nessa direção, ambientes alimentares restritos em termos da disponibilidade de alimentos saudáveis e com preços acessíveis têm sido reconhecidos por estimularem escolhas alimentares inadequadas (Lytle, 2009; Lucan e Mitra, 2012).

Assim, ao reforçar a intersetorialidade da temática aqui abordada, pontua-se a importância de se considerar que a ausência de políticas públicas de abastecimento alimentar pode limitar a disponibilidade de alimentação saudável, empobrecendo o ambiente alimentar, especialmente em territórios de maior vulnerabilidade (Duran et al., 2013), e comprometendo a realização do DHAA. Reforça-se, portanto, a relevância de que se reveste a ausência da problematização dessa temática no debate do grupo.

Em síntese, em que pese a predominância de uma visão do direito à alimentação a partir da dimensão de proteção contra a fome, ilustrada pela valorização das questões relativas ao acesso ao alimento, destaca-se que as participantes, no curso do debate, expressaram percepções abrangentes embora pouco aprofundadas - sobre o DHAA. Assim, indicaram-se elementos que remetiam aos diversos aspectos que caracterizam uma alimentação adequada, como a adequação nutricional e a diversidade de alimentos, a inocuidade, a adequação cultural, o conhecimento e a informação, a renda e a disponibilidade de outros meios (terra, condições para cultivo, assistência social) para obtenção da alimentação e sua relação com a realização de outros direitos (moradia, saneamento, vestuário etc.).

\section{Das percepções às práticas, os desafios}

Diante dos diversos elementos colocados em pauta pelas participantes como condicionantes da plena realização do DHAA, procurou-se reconhecer como elas lidavam com esse direito em sua prática profissional cotidiana, no âmbito do PNAE, e quais os desafios que enfrentavam nesse processo.

Ao provocar essa discussão, imediatamente foi indicado que:

Eu vejo assim, pensando no conceito de direito à alimentação e na segurança alimentar, quando a gente está no PNAE, tem que ver assim: eu estou organizando o cardápio, né? Então, tenho que pensar em toda legislação e tudo mais, tenho que pensar que estou contribuindo para o DHAA, que não posso fugir dos princípios básicos da alimentação e da segurança alimentar... Acho que o DHAA está bem presente no nosso dia a dia, quando se pensa no cardápio, em ações de educação nutricional... Acho que está bem presente na nossa prática diária (Girassol). 
Na problematização dessa temática, surgiram complementações e oposições que trouxeram novos elementos para o debate, como o papel da família e o papel da escola:

Eu acho assim, o direito está presente na nossa prática profissional, mas a família peca quando a criança sai dali [da escola], né? Porque vejo muitos casos de crianças que têm patologia, por exemplo, que é uma situação que a gente tem que atender, fornecendo alimentação adequada, né? Só que quando sai da escola, não é assim que acontece em casa. Então, a família quer que a escola faça o correto, mas em casa ela não fornece o que a criança deveria ter. Então, acho que é muita obrigação pra escola, muita cobrança, e a parte dos pais, da família, está deixando a desejar (Violeta).

É porque cada dia mais a família está deixando pra escola educar, entende? Fazer muito mais do que seria o papel da escola. Então, as famílias acabam largando, a escola que se vira se a criança tem problema psicológico, visual, nutricional... A escola tem que ir atrás, e é assim a realidade, né? Cada vez mais é dessa forma, são poucas as famílias que estão presentes. Agora, acho que as pessoas precisariam do conhecimento sobre o que comprar, como preparar esses alimentos. Acho que é isso que está faltando bastante para as famílias (Cravo).

E eu vejo que o pessoal não tem muito interesse. Falam: ‘Ah, eu moro lá na linha tal e não consigo ter salada todo dia...' Mas você não tem um espaço pra fazer uma horta? Vai mudando os alimentos conforme a sazonalidade, vai se programando, existe suporte, e parece que eles não têm interesse. Falta um pouco de interesse por parte dos pais também (Bromélia).

Percebeu-se, nesse ponto, um movimento na direção da responsabilização das famílias, revestido de certa culpabilização. Sobre esta questão, é preciso considerar que, em condições de vulnerabilidade econômica, o acesso aos alimentos pode estar garantido e não ser suficiente para assegurar uma alimentação adequada (Panigassi et al., 2008), devido à usual diminuição da qualidade da dieta das famílias com o propósito de preservar quantidades de alimentos condizentes com a proteção contra a fome (Poblacion et al., 2014).

Contudo, é pertinente também ponderar que, de fato, o acesso à informação precisa estar garantido, e ainda refletir sobre a alegada falta de interesse das famílias dos escolares em acessar as informações disponíveis e aplicá-las na transformação de suas condições de vida, como indicado pelas falas apresentadas. Nessa direção, pressupor que todos têm acesso a informações suficientes sobre uma alimentação adequada pode não corresponder à realidade, especialmente quando não há um movimento planejado e orgânico visando envolver as famílias nesse debate: 
Enquanto programa de alimentação escolar, enquanto cabe a nós naquele instante em que eles estão na unidade escolar... Depois, fora disso, a gente tenta repassar informações que eles levem para os pais, mas garantir... A gente não pode dizer que atinge o direito à alimentação (Girassol).

É verdade! Uma coisa errada que a gente faz na escola é isso: trabalhar só com as crianças. Agora, há pouco tempo, que está começando a se pensar em fazer um trabalho com os pais. Senão, antes, só com as crianças. E não tem resultado! Na verdade, o que tem que focar é a família, pois a criança vai aprender, mas vai chegar em casa e comer o que tem pra comer... (Cravo).

Constatou-se que o grupo não se via corresponsável pela realização do DHAA fora do ambiente escolar, desconsiderando as numerosas possibilidades de contribuição para a conquista de avanços quanto à realização desse direito a partir do PNAE junto às famílias, por exemplo. Tais achados corroboram o relato de Cervato-Mancuso e colaboradores (2013), no sentido de que há uma desconexão entre o ambiente familiar, o escolar e a sociedade no que tange ao direito à alimentação, uma vez que sua relação com a alimentação escolar não costuma ser discutida pelos diferentes atores envolvidos.

No fluxo da discussão do grupo, foi apresentado um contraponto à posição de responsabilização das famílias por falta de interesse, indicando que o acesso à informação adequada pode não estar garantido e, ainda, reconhecendo que este pode não ser o principal desafio que se apresenta para enfrentamento:

Essa questão - do direito e da segurança alimentar - é uma coisa muito ampla, porque pra garantir uma alimentação adequada vai ter que ir lá educar... Toda essa questão da SAN e do DHAA, até aonde a gente consegue ir, chegar no direito? Fazendo nossa parte na escola, a gente consegue, digamos, garantir esse direito, no acesso. Mas essa questão de fora dali é muito além da família. É muito distante, nas casas, essas questões. Eu acho bem difícil garantir um direito a uma coisa que depende de tantas outras coisas... (Tulipa).

Nesse momento de reflexão, também os professores eram indicados como atores importantes no âmbito do DHAA, considerados pelo grupo como referências para os escolares, inclusive no que se referia às escolhas alimentares, evidenciando a existência de conflitos sobre a oferta de alimentos de qualidade e a importância do incentivo a bons hábitos alimentares na escola:

E tem que trabalhar 'contra' os professores também, né? A nossa luta contra as festinhas... No início, eu tentei trocar os alimentos das festinhas. Muitas escolas preferiram, então, não fazer festinha a fazer festinha saudável, porque queriam 
refrigerante, pastel frito, brigadeiro, e não aceitaram a sugestão de ter um suco natural, um bolo de cenoura... 'Não, então a gente não quer.' Isso que são professores, que têm conhecimento... (Margarida).

Observa-se, aqui, que o grupo reconheceu o papel fundamental que a família e a escola exerciam sobre as variáveis que condicionam as escolhas alimentares e que promovem alimentação adequada. Contudo, pareceu haver limitações para o trabalho em equipe, para mobilizar a comunidade escolar, assumindo-se posições de embate e restando uma atuação do nutricionista circunscrita à escola, traduzida - nesse ambiente - em ações voltadas apenas para os escolares. Esses achados condizem com os de Pacheco e Ramos (2014), que relataram uma atuação do nutricionista no Sistema Único de Saúde caracterizada por ações no nível individual e restritas ao espaço físico das unidades de saúde, o que as autoras concluíram ser reflexo de uma formação acadêmica fragmentada e biologicista que dificulta o trabalho em equipe e a aproximação com a comunidade.

Esse contexto reforça a ideia de que a incorporação da perspectiva do DHAA à alimentação escolar requer a articulação dos diferentes atores envolvidos, empenhados em ampliar a compreensão do PNAE como instrumento de promoção de direitos e de SAN, de forma que as diretrizes do programa possam se traduzir no dia a dia da comunidade escolar como recursos para a cidadania (Cervato-Mancuso et al., 2013).

Ao refletirem coletivamente sobre o DHAA - o que foi propiciado pelo encontro do grupo -, as participantes divergiram em alguma medida sobre a própria contribuição para a realização do direito dos escolares à alimentação, como demonstraram os trechos a seguir:

Claro que não tem como chegar e dizer: 'ah, eu estou garantindo o direito à alimentação lá na escola'. Não tem como, não é uma coisa que depende só da gente! (Cravo).

Olha, eu acho que o próprio PNAE, quando a gente faz controle de qualidade na preparação da alimentação escolar, quando realiza treinamento com as merendeiras, a própria elaboração do cardápio, a educação nutricional, acho que essas funções básicas nossas já contribuem pra garantir o DHAA... (Girassol).

Essas falas reafirmaram a pertinência de que seja iniciado um movimento de aproximação entre os diferentes atores da comunidade escolar - estudantes, famílias, professores, gestores, nutricionistas - que propicie a superação de abordagens técnicas das questões alimentares, limitadas ao fazer específico do nutricionista, desconectadas da realidade social (Ramos e Cuervo, 2012) e que não reconhecem as pessoas como sujeitos de direitos (Albuquerque, 2009), mas como beneficiários, ou usuários, de um programa. 
Inseridas nessa realidade, surgiu alguma insatisfação com a própria prática, indicando uma percepção de que resulta infrutífera e desmotivadora:

É, fazer a gente faz um monte de coisa. O problema é que a gente se decepciona com os resultados do que faz... (Girassol).

Diante dessa fala, o grupo foi incentivado a refletir sobre que outras ações, não abordadas até então, desenvolvia e que contribuíam para a realização do DHAA. Alguns exemplos são apresentados a seguir:

Eu e a agrônoma fomos fazer uma palestra numa área rural. Era justamente pra incentivar a fazer horta, e tinha espaço, tinha tudo, sabe? Agora, a gente voltou lá. Adivinha quem fez a horta? Nossa, foi bem assim, a gente se desanimou, porque foi tão legal e eles participaram, mas pôr em prática...? Incentivamos a produzirem pão, por exemplo: puxa, moram longe da cidade, né? Responderam: 'Ah, mas passa uma camionete vendendo bolacha... É muito mais prático!' (Orquídea).

E na semana da criança tem que fazer atividades do Programa Saúde na Escola. A ideia é fazer rua de lazer, uma atividade que envolva as crianças, né? Com atividades diferenciadas da aula normal. Vamos usar o teatro sobre a questão da alimentação (Girassol).

Nós estamos encaminhando, ainda, o projeto pra fazer uma parceria com o pessoal da educação física, da academia, o médico... Vamos fazer oficinas culinárias, trabalhos diversos, pra que eles possam entender a importância de uma alimentação saudável... Vamos tentar trazer os pais também... (Rosa).

A gente vai fazer uma oficina no contraturno, né? E vamos ter uma reunião com os pais, fazer alguma palestra, alguma orientação pra eles sobre como lidar com a alimentação dessas crianças em casa. Vamos ser eu, o educador físico, a psicóloga (Cravo).

Evidenciou-se nas falas o movimento de buscar alternativas - de atividades, de público, de parcerias - na direção de promover melhorias na alimentação dos estudantes que extrapolem a refeição escolar e alcancem a comunidade. Porém, todos os exemplos citados remeteram a um fazer prescritivo centrado nas 'normas da alimentação saudável' e desenvolvido em uma perspectiva de transmissão do saber, mesmo quando são utilizadas atividades lúdicas.

Essa abordagem não contribui para a incorporação da perspectiva do DHAA à alimentação escolar, na medida em que o direito não é problematizado 
em suas dimensões e condicionantes, focando-se, apenas e parcialmente, na adequação da alimentação. Esse 'modo de fazer', em síntese, não prioriza a dignidade humana, percebendo indivíduos e coletivos como objetos de uma política pública (Albuquerque, 2009). Parafraseando Valente, Franceschini e Burity (2007), para a promoção do DHAA o processo é tão importante quanto os resultados, o que significa que o fato de uma política pública atingir seus objetivos não é suficiente, tornando-se fundamental considerar como esses objetivos estão sendo alcançados.

Nessa lógica, cabe destacar a ausência de qualquer menção a iniciativas que visem à incorporação das temáticas pertinentes ao DHAA ao currículo escolar, por meio da articulação com os fazeres dos professores, usufruindo do espaço proposto pela abordagem dos temas transversais (Brasil, 1997). Argumenta-se que essa articulação com o currículo formal da escola proporciona problematização e, assim, contribui para o desenvolvimento da consciência e motivação para transformar a realidade, promovendo a construção do conhecimento e superando sua mera transmissão (Albuquerque, Pontes e Osório, 2013). Ao trazer essa perspectiva para o espaço escolar, integrando a abordagem do DHAA, o PNAE pode ir além de promover acesso à alimentação por meio de uma prática centrada na relação entre alimentos e seus nutrientes, constituindo-se em espaço de construção de autonomia e de cidadania (Barbosa et al., 2013).

Dando continuidade à reflexão sobre os desafios apresentados à promoção do DHAA no cotidiano do PNAE, emergiu fortemente a questão da intersetorialidade:

Não há muitas ações dos outros setores, de forma articulada... Então essa que é a nossa dificuldade (Dália).

Mas existem ações, né? Em cada município existem as ações da saúde, da assistência social, na educação também, e a agricultura... O complicado é se fazer uma integração... É uma realidade de todos os lugares essa questão política. Isso é uma coisa que impede bastante de dar continuidade. A gente começa um trabalho, aí muda tudo... É bem complicada essa questão. Então, não é só: 'ah, eu tenho vontade, eu vou fazer'. Não é assim, tudo depende de vários fatores, das pessoas que estão envolvidas, da vontade. Essa questão da articulação é bem difícil, os trabalhos são bem individuais, né? (Cravo).

Não existe vínculo entre as secretarias... Muitos secretários são novos, né? (Rosa).

As falas apresentadas explicitaram a intersetorialidade como um dos maiores desafios enfrentados pelas participantes no cotidiano de sua atuação profissional no PNAE. A esse respeito, Alves e Jaime (2014) afirmam 
que a incorporação da intersetorialidade nas políticas públicas desse campo requer a articulação de diferentes áreas técnicas de governo em um processo de integração de agendas coletivas e compartilhamento de objetivos, com potencial para produzir melhores condições para garantia de direitos à população. Contudo, as autoras fazem a ressalva de que a intersetorialidade também coloca em cena novos desafios, na medida em que é preciso superar a fragmentação e a desarticulação que usualmente emergem nos espaços de negociação e construção compartilhada.

Dito de outra forma, entre os principais desafios apresentados para a conquista da intersetorialidade requerida pelas políticas públicas contemporâneas na área do DHAA e da SAN, destacam-se os atores envolvidos na concretização dessas políticas e sua prática social. Na mesma direção, Magalhães (2014) postula que as instituições governamentais são permeadas por disputas e conflitos de ordem política, o que pode limitar a autonomia no trabalho com as políticas públicas. Já para Burlandy (2009), a promoção da intersetorialidade é uma tarefa desafiadora, que exige a mobilização de diferentes mecanismos, processos e instrumentos institucionais.

São inegáveis os desafios apresentados pela conquista da intersetorialidade no âmbito das políticas públicas. Contudo, os achados deste estudo, no seu conjunto, instigam um movimento de 'dar um passo atrás' para refletir sobre possíveis mecanismos de enfrentamento desse e de outros desafios que emergiram da análise.

As percepções abrangentes, mas pouco fundamentadas teórica e politicamente, sobre o DHAA evidenciaram um campo fértil para que sejam promovidos processos de educação permanente em torno dessas temáticas. No entanto, é fundamental que seja considerada a formação proporcionada pelo ensino superior, reconhecidamente ainda focada em competências técnicas em detrimento das humanísticas e desarticulada quanto ao dilema teoria-prática, em prejuízo de uma atuação profissional pautada pelos princípios do direito humano à alimentação (Vieira, Utikava e Cervato-Mancuso, 2013).

Tais ponderações foram reforçadas, na pesquisa que deu origem a este artigo, quando se lançou um olhar sobre as práticas desenvolvidas a partir do PNAE e sua relação com o DHAA. O caráter normativo e prescritivo das práticas, assim como sua direção unilateral - partindo-se de um ponto em que se detém o saber e dirigindo-se a outro ponto, onde se pressupõe que o saber precise chegar -, condiz com a carência de fundamentação constatada quanto aos elementos implicados com o DHAA. Argumenta-se que essas práticas são a tradução possível das percepções sobre o DHAA na realidade cotidiana dos diversos atores sociais envolvidos no PNAE.

Assim, ao se propor 'dar um passo atrás' e refletir sobre a formação profissional, sugere-se que sua natureza fragmentada e biologicista contribui para um engessamento das ações no âmbito das políticas públicas, 
evidenciando-se a importância de que os profissionais que atuam nessa área, conectados à realidade social dos sujeitos de direitos, superem a mecanização de suas práticas com vistas à promoção do DHAA (Ramos e Cuervo, 2012). Nessa direção, uma estratégia para qualificar os processos de formação profissional na área da nutrição pode ser a sua politização, de forma a contribuir para uma atuação pautada pelos princípios da SAN, que incorpore a perspectiva do DHAA (Vieira, Utikava e Cervato-Mancuso, 2013).

\section{Considerações finais}

A análise dos achados evidenciou uma percepção abrangente sobre o DHAA, em suas diferentes dimensões e quanto às relações com os aspectos inerentes à alimentação adequada. Também emergiu do processo de pesquisa a percepção sobre a importância de os diferentes atores e setores envolvidos com o PNAE atuarem de forma articulada e intersetorial, compartilhando responsabilidades na promoção do DHAA e da SAN.

No entanto, ao serem exploradas as percepções sobre o DHAA, observou-se certa fragilidade de suporte teórico e político, o que pareceu se traduzir no campo das práticas, no como fazer, como intervir para transformar a realidade. Nesse sentido, além das limitações para estabelecer, consolidar e garantir a continuidade de uma ação intersetorial e articulada à comunidade escolar, emergiu da análise uma fragilidade em termos de instrumentação teórico-metodológica para a intervenção nesse campo. As intervenções surgiram, no mais dos exemplos debatidos, valendo-se de metodologias tradicionais de perspectiva verticalizada, embasadas na lógica da transmissão do conhecimento, produzindo pouca ou nenhuma mudança na realidade e desmotivando os sujeitos para a ação.

Na problematização desse cenário, sugere-se a premência de que sejam promovidas ações de educação permanente visando à qualificação da atuação profissional nas diferentes realidades em que essa e outras políticas públicas são implementadas. Contudo, também é fundamental que essa discussão alcance os espaços em que se desenvolve o ensino superior em nutrição, de forma a promover melhorias na formação com base nos aprendizados produzidos pelos processos de pesquisa, conferindo-lhes sentido e relevância social e contribuindo para um perfil de egresso mais politizado e articulado às demandas da realidade. Nessa direção, argumenta-se que a incorporação do paradigma da educação popular possa contribuir para um movimento efetivo de qualificação da formação profissional.

Conclusivamente, propõe-se que o grande desafio a ser enfrentado se situa nesse campo - o da formação profissional -, tanto no nível do ensino superior quanto no da educação permanente. Logo, estudos sobre expe- 
riências e singularidades locais ou profissionais podem ser estratégicos no movimento de delinear processos inovadores de formação e de trabalho que promovam a incorporação da perspectiva dos direitos e da cidadania às políticas públicas afetas à alimentação e nutrição.

\section{Colaboradores}

Carla Rosane Paz Arruda Teo e Luciara Souza Gallina participaram da concepção do estudo, da coleta e da análise de dados, da redação do texto e da aprovação da versão final. Maria Assunta Busato participou da análise de dados, da redação do texto e da aprovação da versão final. Taíne Paula Cibulski e Tamara Becker participaram da coleta e da análise de dados, da redação do texto e da aprovação da versão final.

Resumen La incorporación de la perspectiva de los derechos y la ciudadanía a las políticas públicas de alimentación y nutrición pasa por la práctica social de los actores involucrados con la concreción de estas políticas. El objetivo del estudio aquí presentado fue comprender las percepciones y las prácticas de nutricionistas sobre el derecho humano a la alimentación adecuada en el ámbito de su actuación profesional en el Programa Nacional de Alimentación Escolar. El estudio, realizado en 2014, fue de naturaleza cualitativa, y la recolección de datos, realizada por un grupo focal. Participaron 11 nutricionistas de municipios de la Mesoregión Oeste Catarinense (Brasil). Las respuestas se grabaron, se transcribieron y se analizaron según la técnica de análisis de contenido temático. Los resultados indicaron que los participantes tenían una percepción abarcativa sobre el derecho humano a la alimentación adecuada, en diferentes dimensiones y relaciones con los aspectos inherentes a la misma. Las nutricionistas destacaron la importancia y el desafío de la actuación intersectorial, articulada a la comunidad. Sin embargo, pareció haber una limitación al trabajo en equipo y a la interlocución con las familias, posiblemente por la fragilidad del soporte teórico-metodológico y político para intervenir en ese campo. Las percepciones abarcativas de las nutricionistas, pero poco fundamentadas teórica y políticamente sobre el derecho humano a la alimentación adecuada, pusieron de manifiesto el desafío a ser enfrentado en la formación profesional, tanto en el pregrado como en la educación permanente.

Palabras clave alimentación escolar; acción intersectorial; derechos humanos; educación superior; políticas públicas. 


\title{
Notas
}

\author{
1 Universidade Comunitária da Região de Chapecó, Programa de Pós-Graduação em \\ Ciências da Saúde, Chapecó, Santa Catarina, Brasil. \\ $<$ carlateo21@gmail.com> \\ Correspondência: Universidade Comunitária da Região de Chapecó, Área de Ciências \\ da Saúde, Avenida Senador Attilio Fontana, 591-E, Efapi, CEP 89809-000, Chapecó, \\ Santa Catarina, Brasil. \\ 2 Universidade Comunitária da Região de Chapecó, Curso de Graduação em Nutrição, \\ Chapecó, Santa Catarina, Brasil. \\ <luciara@unochapeco.edu.br> \\ 3 Universidade Comunitária da Região de Chapecó, Programa de Pós-Graduação em \\ Ciências da Saúde, Chapecó, Santa Catarina, Brasil. \\ <assunta@unochapeco.edu.br> \\ 4 Universidade de Passo Fundo, Residência Multiprofissional Integrada em Atenção \\ ao Câncer, Passo Fundo, Rio Grande do Sul, Brasil. \\ $<$ tainecibulski@gmail.com> \\ 5 Universidade de Passo Fundo, Residência Multiprofissional Integrada em Saúde do \\ Idoso, Passo Fundo, Rio Grande do Sul, Brasil. \\ $<$ nutricionistatamara@gmail.com>
}

\section{Referências}

ALBUQUERQUE, Alicinez G.; PONTES, Cleide M.; OSÓRIO, Mônica M. Knowledge of educators and dieticians on food and nutrition education in the school environment. Revista de Nutrição, Campinas, v. 26, n. 3, p. 291-300, maio-jun. 2013.

ALBUQUERQUE, Maria F. M. A segurança alimentar e nutricional e o uso da abordagem de direitos humanos no desenho das políticas públicas para combater a fome e a pobreza. Revista de Nutrição, Campinas, v. 22, n. 6, p. 895-903, nov.-dez. 2009.

ALVES, Kelly P. S.; JAIME, Patricia C. A Política Nacional de Alimentação e Nutrição e seu diálogo com a Política Nacional de Segurança Alimentar e Nutricional. Ciência \& Saúde Coletiva, Rio de Janeiro, v. 19, n. 11, p. 937-945, nov. 2014.
BARBOSA, Najla V. S. et al. Alimentação na escola e autonomia: desafios e possibilidades. Ciência \& Saúde Coletiva, Rio de Janeiro, v. 18, n. 4, p. 937-945, abr. 2013.

BELIK, Walter. Perspectivas para segurança alimentar e nutricional no Brasil. Saúde e Sociedade, São Paulo, v. 12, n. 1, p. 12-20, jan.-jun. 2003.

BRASIL. Presidência da República. Casa Civil. Subchefia para Assuntos Jurídicos. Constituição da República Federativa do Brasil de 1988. Brasília: Casa Civil, 1988. Disponível em: <www.planalto.gov.br/ccivil_03/ Constituicao/Constituicao.htm $>$. Acesso em: 13 out. 2016.

BRASIL. Decreto n. 591, de 6 de julho de 1992. Atos Internacionais. Pacto Internacional 
sobre Direitos Econômicos, Sociais e Culturais. Promulgação. Diário Oficial da União, Brasília, DF, 7 jul. 1992. Disponível em: <www. planalto.gov.br/ccivil_03/decreto/1990-1994/ D0591.htm>. Acesso em: 11 mar. 2014.

BRASIL. Ministério da Educação. Secretaria de Educação Fundamental. Parâmetros curriculares nacionais: introdução aos parâmetros curriculares nacionais. Brasília: MEC/SEF, 1997.

BRASIL. Lei n. 11.346, de 15 de setembro de 2006. Cria o Sistema Nacional de Segurança Alimentar e Nutricional-Sisan com vistas em assegurar o direito humano à alimentação adequada e dá outras providências. Diário Oficial da União, Brasília, DF, 18 set. 2006. Disponível em: <www.planalto. gov.br/ccivil_03/_ato2004-2006/2006/lei/ 111346.htm>. Acesso em: 10 dez. 2014.

BRASIL. Conselho Nacional de Segurança Alimentar e Nutricional (Consea). Construção do Sistema e da Política Nacional de Segurança Alimentar e Nutricional: a experiência brasileira. Brasília: Consea, 2009.

BRASIL. Emenda constitucional n. 64, de 4 de fevereiro de 2010a. Altera o art. $6^{\circ}$ da Constituição Federal, para introduzir a alimentação como direito social. Diário Oficial da União, Brasília, DF, 5 fev. 2010. Disponível em: <www.planalto.gov.br/ccivil_03/ constituicao/Emendas/Emc/emc64.htm>. Acesso em: 23 nov. 2013.

BRASIL. Conselho Nacional de Segurança Alimentar e Nutricional (Consea). A segurança alimentar e nutricional e o direito humano à alimentação adequada no Brasil: indicadores e monitoramento da Constituição de 1988 aos dias atuais. Brasília: Consea, 2010b.

BRASIL. Ministério da Saúde. Conselho Nacional de Saúde. Resolução n. 466, de 12 de dezembro de 2012. Brasília: Ministério da Saúde, 2012. Diário Oficial da União, Brasília, DF, 13 jun. 2013. Disponível em: <http:// bvsms.saude.gov.br/bvs/saudelegis/cns/ 2013/res0466_12_12_2012.html>. Acesso em: 2 mar. 2016.
BRASIL. Ministério da Saúde. Secretaria de Vigilância em Saúde. Vigitel Brasil 2013: vigilância de fatores de risco e proteção para doenças crônicas por inquérito telefônico. Brasília: Ministério da Saúde, 2014.

BURLANDY, Luciene. A construção da política de segurança alimentar e nutricional no Brasil: estratégias e desafios para a promoção de intersetorialidade no âmbito federal do governo. Ciência \& Saúde Coletiva, Rio de Janeiro, v. 14, n. 3, p. 851-860, maio-jun. 2009.

CERVATO-MANCUSO, Ana M. et al. School feeding programs' role in forming eating habits. Revista Paulista de Pediatria, São Paulo, v. 31, n. 3, p. 324-330, set. 2013.

CHAVES, Lorena. G. et al. Programa Nacional de Alimentação Escolar: compromisso com a saúde pública. Nutrição Profissional, São Paulo, v. 3, n. 12, p. 22-27, abr. 2007.

DURAN, Ana C. et al. Neighborhood socioeconomic characteristics and differences in the availability of healthy food stores and restaurants in São Paulo, Brazil. Health \& Place, New York, v. 23, p. 39-47, set. 2013.

FOOD AND AGRICULTURAL ORGANIZATION (FAO). O direito humano à alimentação adequada no marco estratégico global para a segurança alimentar e nutricional: consenso global. Roma: FAO, 2014. Disponível em: $<$ www.fao.org/3/a-i3546o.pdf > . Acesso em: 13 out. 2016.

FUNDO NACIONAL DE DESENVOLVIMENTO DA EDUCAÇÃO (FNDE). Alimentação escolar: dados estatísticos. 2013. Disponível em: <www. fnde.gov.br/programas/alimentacao-escolar/ item/5097-dados-estatisticos $>$. Acesso em: 13 out. 2016.

GATTI, Bernadete A. Grupo focal na pesquisa em ciências sociais e humanas. Brasília: Liber, 2012.

INSTITUTO BRASILEIRO DE GEOGRAFIA E ESTATÍSTICA (IBGE). Pesquisa de orçamentos familiares 2008-2009: antropometria e estado nutricional de crianças, adolescentes 
e adultos no Brasil. 2010. Disponível em: $<$ http://biblioteca.ibge.gov.br/visualizacao/ livros/liv45419.pdf> Acesso em: 13 out. 2016.

INSTITUTO BRASILEIRO DE GEOGRAFIA E ESTATÍSTICA (IBGE). Estimativas de população para $1^{\circ}$ de julho de 2014 . Disponível em: <www.ibge.gov.br/home/estatistica/ populacao/estimativa2014/estimativa_tcu. shtm>. Acesso em: 19 nov. 2014.

KEPPLE, Anne W.; SEGALL-CORRÊA, Ana M. Conceituando e medindo a segurança alimentar e nutricional. Ciência \& Saúde Coletiva, Rio de Janeiro, v. 16, n. 1, p. 187-199, jan. 2011.

LEÃO, Marília M.; RECINE, Elisabetta. O direito humano à alimentação adequada. In: TADDEI, José A. et al. Nutrição em saúde pública. São Paulo: Rubio, 2011. p. 471-488.

LUCAN, Sean C.; MITRA, Nandita. Perceptions of the food environment are associated with fast-food (not fruit-and-vegetable) consumption: findings from multi-level models. International Journal of Public Health, Switzerland, v. 57, n. 3, p. 599-608, jun. 2012.

LYTLE, Leslie A. Measuring the food environment state of the science. American Journal of Preventive Medicine, Washington, v. 36, n. 4S, p. S134-S144, abr. 2009.

MACHADO, Felipe R. S. O direito à saúde na interface sociedade civil e Estado. Trabalho, Educação e Saúde, Rio de Janeiro, v. 7, n. 2, p. 355-371, jul.-out. 2009.

MAGALHÃES, Rosana. Avaliação de políticas e iniciativas públicas de segurança alimentar e nutricional: dilemas e perspectivas metodológicas. Ciência \& Saúde Coletiva, Rio de Janeiro, v. 19, n. 5, p. 1.339-1.346, maio 2014.

MALUF, Renato S. J. Direito humano à alimentação adequada e saudável. In: MALUF, Renato S. J. Segurança alimentar e nutricional. 3. ed. Petrópolis: Vozes, 2011. p. 20-21.

MINAYO, Maria C. S. O desafio do conhecimento: pesquisa qualitativa em saúde. 13. ed. São Paulo: Hucitec, 2010.
ORGANIZAÇÃO DAS NAÇÕES UNIDAS (ONU). Declaração Universal dos Direitos Humanos, 1948. Disponível em: <www.dudh.org.br>. Acesso em: $20 \mathrm{dez} .2014$.

ORGANIZAÇÃO DAS NAÇÕES UNIDAS (ONU). Pacto Internacional dos Direitos Econômicos, Sociais e Culturais (Pidesc). 1966. Disponível em: <www.oas.org/dil/port/1966\%20 Pacto \% 20Internacional \% 20sobre \% 20os $\%$ 20Direitos \% 20Econ \% C3\% B3micos, \% 20 Sociais $\% 20 \mathrm{e} \% 20$ Culturais.pdf $>$. Acesso em: 8 jan. 2015 .

ORGANIZAÇÃO DAS NAÇÕES UNIDAS (ONU). Organizações das Nações Unidas. Comentário geral n. 12: o direito humano à alimentação adequada (art. 11). 1999. Disponível em: <http:// pfdc.pgr.mpf.mp.br/atuacao-e-conteudos-deapoio/publicacoes/alimentacao-adequada/ Comentario\%20Geral\%20No\%2012.pdf/ view>. Acesso em: $20 \mathrm{dez} .2014$.

PACHECO, Pauline M.; RAMOS, Maurem. Nutricionista em atenção básica: a visão do usuário. Demetra, Rio de Janeiro, v. 9, n. 2, p. 483-501, maio/ago. 2014.

PANIGASSI, Giseli et al. Insegurança alimentar intrafamiliar e perfil de consumo de alimentos. Revista de Nutrição, Campinas, v. 21, supl., p. 135-144, jul./ago. 2008.

POBLACION, Ana P. et al. Insegurança alimentar em domicílios brasileiros com crianças menores de cinco anos. Cadernos de Saúde Pública, Rio de Janeiro, v. 30, n. 5, p. 1.067-1.078, maio 2014.

PROGRAMA DAS NAÇÕES UNIDAS PARA O DESENVOLVIMENTO (PNUD). Atlas de desenvolvimento humano. 2013. Disponível em: <www.pnud.org.br/IDH/Atlas2003. aspx?indiceAccordion $=1 \&$ li $=$ li_Atlas $>$. Acesso em: 31 jul. 2014.

RAMOS, Camila I.; CUERVO, Maria R. M. Programa Bolsa Família: a interface entre a atuação profissional e o direito humano à alimentação adequada. Ciência \& Saúde Coletiva, Rio de Janeiro, v. 17, n. 8, p. 2.159-2.168 , ago. 2012. 
SIQUEIRA, Renata L. et al. Análise da incorporação da perspectiva do direito humano à alimentação adequada no desenho institucional do Programa Nacional de Alimentação Escolar. Ciência \& Saúde Coletiva, Rio de Janeiro, v. 19, n. 1, p. 301-310, jan. 2014.

VALENTE, Flávio L. S. O combate à fome e a desnutrição e a promoção da alimentação adequada no contexto do direito humano à alimentação: um eixo estratégico do desenvolvimento humano sustentável. São Paulo: Instituto da Cidadania, 2001.

VALENTE, Flávio L. S. Segurança alimentar e nutricional: transformando natureza em gente. In: Direito à alimentação: desafios e conquistas. São Paulo: Cortez, 2002. p. 103-136.

VALENTE, Flávio L. S.; BEGHIN, Nathalie. Realização do direito humano à alimentação adequada e a experiência brasileira: subsídios para a replicabilidade. Brasília: FAO, 2006.
VALENTE, Flávio L. S.; FRANCESCHINI, Thaís; BURITY, Valéria. A exigibilidade do direito humano à alimentação adequada. Brasília: Abrandh, 2007. Disponível em: $<$ www.bvsde.paho.org/texcom/nutricion/ exigibilidade.pdf $>$. Acesso em: 13 out. 2016.

VIEIRA, Viviane L.; UTIKAVA, Natália; CERVATO-MANCUSO, Ana M. Atuação profissional no âmbito da segurança alimentar e nutricional na perspectiva de coordenadores de cursos de graduação em nutrição. Interface: Comunicação, Saúde, Educação, Botucatu, v. 17, n. 44, p. 157-170, jan.-mar. 2013.

Recebido em 20/02/2015

Aprovado em 04/03/2016 